\title{
A non-randomized controlled effectiveness study of a smoking cessation intervention for adolescents
}

\author{
Anneke Bühler ${ }^{1}$, Johannes Thrul ${ }^{2}$, Michaela Goecke³, Annette Schmidt 4 \\ Hochschule für angewandte Wissenschaften, Kempten \\ Johns Hopkins University, Baltimore \\ Bundeszentrale für gesundheitliche Aufklärung (BZgA), Köln \\ 4 IFT Institut für Gesundheitsförderung, München
}

Summary: Despite a remarkable decrease of smoking prevalence among German teenagers over the last 20 years, a substantial number of adolescents report current cigarette use, especially youth with low socioeconomic status. This study investigated the effectiveness of a school-based psychosocial adolescent smoking cessation intervention under real-world conditions.

Methods: The intervention consisted of six sessions of school-based group counseling, using motivational enhancement and cognitive-behavioral content, along with 4 weeks of follow-up care by text messaging and phone calls. A total of 47 smoking cessation classes were implemented in secondary schools all over Germany. The intervention group (IG) consisted of 272 currently smoking students nested in 41 schools, and the control group (CG) comprised 240 currently smoking students nested in 10 schools. Assignment to IG and CG was non-randomized. Logistic regression analyses (complete case, intention to treat, and full-information-maximum-likelihood) were conducted to test group differences in past 30-day smoking abstinence at 6-month follow-up. Baseline differences between IG and CG and intraclass correlation were accounted for in the analyses.

Results: There were no differences in school characteristics between IG and CG schools at baseline. At 6-month follow-up, the IG had a significantly higher abstinence rate than the CG (Intent-totreat analysis: $14 \%$ IG vs. $5 \%$ CG; adjusted odds ratio $=2.73$; $95 \%$ confidence interval: $1.19-6.27$ ). Results were consistent for complete case and full-information-maximum-likelihood analyses.

Conclusions: Results suggest that school-based psychosocial interventions can be feasible and effective for smoking cessation among adolescents in schools with a higher proportion of youth with low socioeconomic status.

Keywords: Tobacco; youth; smoking cessation; effectiveness

\section{Eine kontrollierte Wirksamkeitsstudie des „losgelöst“-Rauchstoppkurses für Jugendliche}

Zusammenfassung: Trotz einer bemerkenswerten Abnahme der Rauchprävalenz unter deutschen Teenagern während der letzten 20 Jahre raucht noch immer eine substanzielle Anzahl an Jugendlichen, insbesondere solche in sozial benachteiligten Lagen. Die vorliegende Studie überprüft die Wirksamkeit einer schulbasierten, psychosozialen Rauchstopp-Intervention unter Feldbedingungen.

Methode: Die Gruppenintervention bestand aus sechs Sitzungen, die v. a. auf Motivationsförderung abzielten und kognitiv-behaviorale Methoden vermittelten. Ihnen folgte eine vierwöchige Nachsorgephase per SMS und telefonischem Kontakt. Geschulte Trainer und Trainerinnen führten bundesweit insgesamt 47 Rauchstopp-Kurse in Haupt- und Realschulen durch. Die Interventionsgruppe (IG) bestand aus 272 aktuell rauchenden Jugendlichen an 41 Schulen, die Kontrollgruppe (KG) aus 240 Jugendlichen an 10 Schulen. Die Zuordnung zu IG und KG erfolgte nicht randomisiert. Logistische Regressionen (complete case, intent-to-treat und full-information-maximum-likelihood) wurden berechnet, um Gruppenunterschiede in der 30-Tage-Abstinenz zur 6-Monats-Nachbefragung zu überprüfen. Ausgangsunterschiede zwischen IG und KG sowie Intraklassenkorrelationen wurden in den Analysen berücksichtigt. 
Ergebnisse: Zu Beginn der Studie unterschieden sich Interventions- und Kontrollschulen nicht. Zur 6-Monats-Nachbefragung wies die IG eine signifikant höhere Abstinenzrate auf als die KG (Intentto-treat-Analyse: $14 \%$ in IG versus $5 \%$ in KG, adjustierte Odds Ratio $=2.73,95 \%$ Konfidenzintervall: 1.19-6.27). Die Ergebnisse wurden durch complete-cases und full-information-maximum-likelihood Analysen gestützt.

Schlussfolgerung: Die Ergebnisse legen nahe, dass Rauchstopp-Kurse mit Jugendlichen in Hauptund Realschulen machbar und wirksam sein können.

Schlüsselbegriffe: Rauchen, Jugendliche, Rauchstopp, Schule, Wirksamkeit

Over the last two decades, smoking prevalence among German 12 to 17 -year-old teenagers has decreased dramatically: Self-reported smoking declined from $27,5 \%$ in 2001 to $7,4 \%$ in 2016 (Orth \& Merkel, 2018). However, there are differences in smoking rates by socio-economic status (SES), with fewer current smokers among teenagers with high SES (4\%) compared to middle $(7,9 \%)$ or low SES $(8,0 \%)$ (Kuntz, Waldhauer, Zeiher, Finger \& Lampert, 2018). Moreover, rates are still substantial among older adolescents, with about $20 \%$ of 17 year olds reporting current smoking (Zeiher, Lange, Starker, Lampert \& Kuntz, 2018). Previous research indicates that approximately one third of adolescent smokers are motivated to reduce or stop their tobacco use, but rarely think about utilizing professional smoking cessation support (Bühler \& Thrul, 2012). Thus, the German Federal Centre for Health Education (BZgA) commissioned the development and evaluation of a smoking cessation intervention that is attractive and effective for adolescents with lower SES.

\section{Theories used in designing the intervention}

The program "losgelöst" (Engl.: "detached") was designed in accordance with effectiveness research on adolescent smoking cessation interventions (ASCI). The most stringent and recent review of adolescent interventions (Fanshawe et al., 2017) found moderate effects for interventions based on a complex theoretical model combining the stages of change, motivational interviewing, cognitive-behavioral and/or social cognitive theory. Other reviews with wider inclusion criteria recommended ASCIs to combine motivational enhancement, social influence, and cognitive-behavioral components (Sussman \& Sun, 2009; Simon, Kong, Cavallo \& Krishnan-Sarin, 2015). Therefore, "losgelöst" was developed based on motivational, social influence, and cognitive-behavioral theory.

Quit rates in ASCIs are low compared to adult cessation interventions (Fanshawe et al., 2017). In order to improve intervention effectiveness, we consulted general theories of adolescent development to identify and develop intervention features tailored to the needs of adolescent smokers. According to the Theory of Life-Course Persistent and Adolescence-Limited Antisocial Behavior (Moffitt, 1993), there is substantial heterogeneity in pathways of problem behaviors, including substance use. More severe tobacco use patterns and pathways are associated with internalizing and externalizing behaviors (Kandel, Hu, Griesler \& Schaffran, 2007). Therefore, the intervention included one individual session to screen for potential problem behaviors in addition to smoking and refer participants to additional support. The Theory of Risk Behavior (Jessor, 1992) states that problem behavior can have functional aspects during adolescence: Substance use may be instrumental when coping with adolescent-specific developmental tasks, including relationship building and identity formation (Brown et al., 2008). Thus, training in interpersonal relationship skills and reflection on questions of identity were part of the interven- 
tion. Finally, the Family Development Model (Schneewind, 2005) and the Model of Adolescent Smoking Cessation proposed by Branstetter and colleagues (2009) both emphasize the importance of parents and siblings during adolescence. Therefore, family members were considered in several modules of the intervention in addition to peers and friends. Pilot study results showed that, compared to students at Gymnasien, students at Hauptschulen and Realschulen reported greater acceptance of this intervention approach and content (e. g., interactive, behavioral rather than cognitive, playful, partly directive, and including music; Bühler, Geier \& Metz, 2009). Thus, the program seemed to work especially well at schools with a higher proportion of students with a lower SES background.

The intervention was previously tested in a feasibility trial with promising results (Bühler et al., 2012). Here, we report the results of an effectiveness study, implementing the intervention under real-world conditions and comparing it to a treatment-as-usual control group.

\section{Methods}

\section{Intervention}

The intervention consisted of 6 sessions over 3 weeks (5 group sessions lasting 90 minutes, 1 individual session lasting 15 minutes), and a follow-up care interval of 4 weeks including booster calls and text messages (Bühler et al., 2012; Thrul, Stemmler, Bühler \& Goecke, 2014; Wegmann, Bühler, Strunk, Lang \& Nowak, 2012). The first session aimed at promoting ambivalence about smoking and at enhancing the motivation to participate in the intervention. The second session identified typical smoking situations and developed alternative behaviors. In the third session, students planned details of their quit day, which was scheduled for all group members between the third and fourth session, and supported by text messages sent to each participant on the quit day. The fourth session consisted of a reflection exercise of the quit day, stabilization of participants' intention to remain smoke-free, information on coping with lapses, as well as gender-specific relapse prevention. The fifth session was a one-on-one conversation between each participant and the trainer, including a discussion of individual difficulties with quitting or additional problems not related to smoking and referral to additional support if needed. The sixth session aimed at clarifying adolescents' self-image and strengthening their nonsmoker identity. During follow-up care, students received one phone call and 5 motivational text messages. All intervention sessions were delivered in schools but after regular school hours.

\section{Procedures}

In 2010, 41 smoking cessation professionals or schoolbased social workers (i.e. the intervention trainers) from 13 of the 16 German states received a 2-day training session in the smoking cessation intervention manual. Intervention trainers self-selected into the study by responding to an announcement e-mail sent to all certified trainers of a national smoking cessation intervention for adults. In order to participate in the study, the smoking cessation professionals had to name a cooperating school and a supporting member of the school staff other than a teacher. Trainers implemented 47 smoking cessation classes at 42 secondary schools (Haupt- and Realschule). Recruitment was targeted to these types of schools because studies have consistently shown that smoking prevalences are highest in Haupt- and Realschulen in Germany (Orth \& Merkel, 2018). Participating students completed a baseline survey before the start of the intervention and additional surveys in each group meeting, at the end of the sixth session, and at the end of the followup care interval of 4 weeks (post-treatment). A followup survey was completed 6 months after the end of the follow-up care. The control group (CG) consisted of smoking students from 10 additional schools and completed baseline and 6-month follow-up surveys. Control schools were identified by trainers, contacted by project staff, and consisted of schools of the same type as intervention schools. Students in the CG received a self-help smoking cessation booklet for adolescents. Baseline and follow-up surveys were conducted by providing questionnaires to entire school classes supervised by trainers or study staff. The usual precautions to maximize validity of self-reports were applied (e.g., anonymity was assured to participants, participants completed questionnaires using codes instead of names, questionnaires were collected by study staff, and envelopes sealed in front of participants). All study procedures were approved by the ethics commission of the German Psychological Society. Parental consent for participation in the study was requested beforehand by letters sent to the schools and distributed by teachers. 


\section{Participants}

We conducted a power analysis assuming a smoking cessation odds ratio (OR) of 2.0 in the IG versus the CG (Sussman, Dent \& Lichtman, 2001), which showed that $N=466$ smokers were needed for $80 \%$ power to detect a significant intervention effect.

In-class information sessions and individual referral by teachers and school social workers were used to recruit participants into the intervention group (IG). Recruitment primarily targeted teens between 14 and 17 years old that had smoked at least one cigarette in the previous 7 days. Incentives for regu- lar participation ( 3 media vouchers, $€ 10$,- each) were used to improve recruitment and intervention engagement, and participation was voluntary (Thrul, Stemmler, Goecke \& Bühler, 2015).

A total of 291 smokers agreed to participate in the intervention. Since the entire intervention data of one class was missing $(n=19)$, the final IG sample analyzed in this study consisted of 272 currently smoking students nested in 41 schools. The CG consisted of 240 students who reported current smoking at baseline and were nested in 10 control schools, for a total sample of $N=512$ participants. The study flow of participants is displayed in Figure 1.

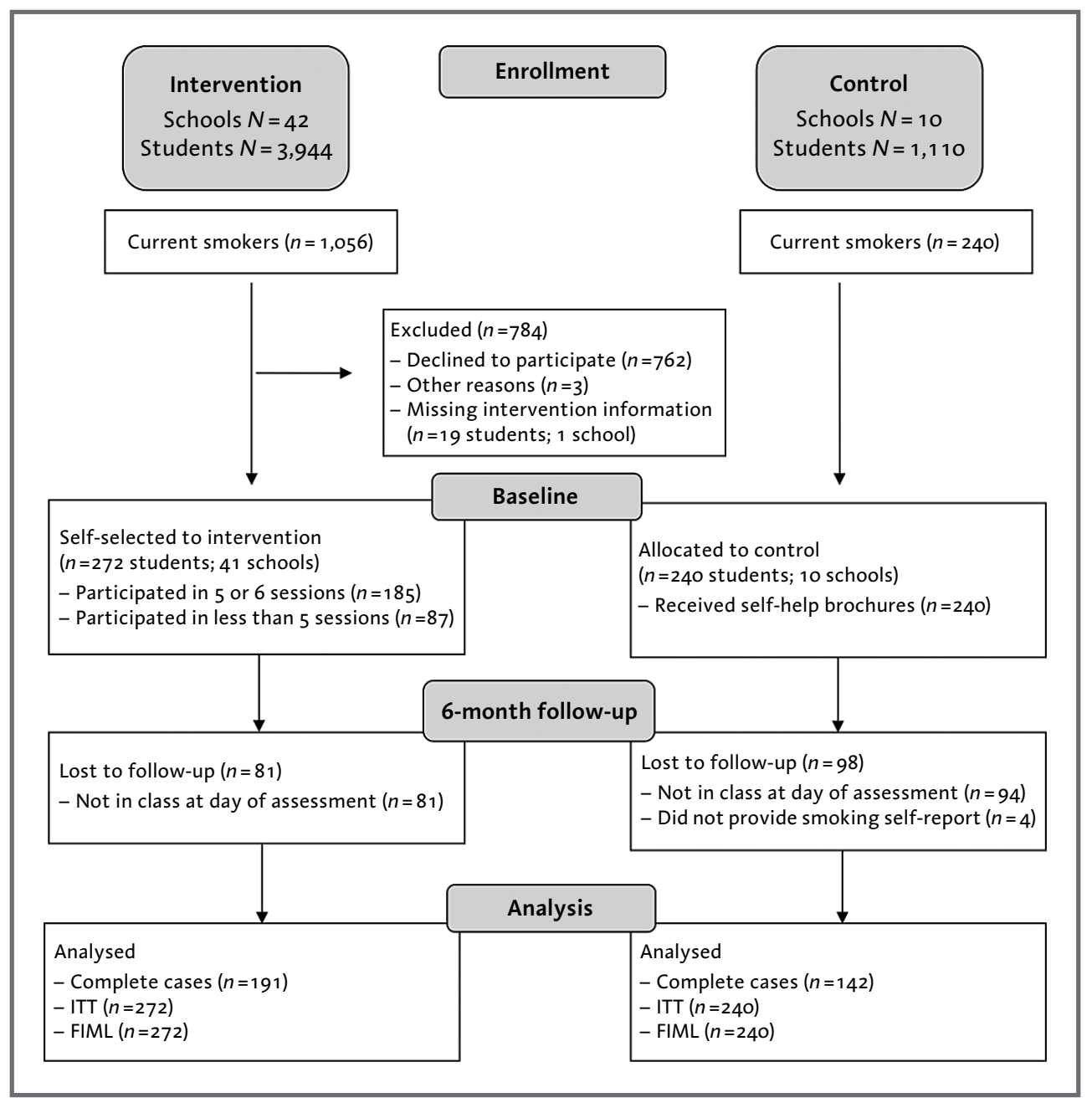

Figure 1: Study flow of participants

Note: FIML = Full Information Maximum Likelihood; ITT = Intention to treat $($ missing $=$ smoking $)$ 


\section{Measures}

Smoking behavior at baseline was assessed with 2 questions. Smoking frequency ("On how many of the last 30 days have you smoked cigarettes?”) and quantity ("How many cigarettes do you usually smoke on a smoking day?"). An index of cigarettes per day (CPD) was calculated ((quantity*frequency)/30) (Kraus, Piontek, Pabst, Gomes de Matos, 2013).

Strength of nicotine dependence was assessed using the German version of the Hooked on Nicotine Checklist (HONC) (DiFranza et al., 2002). The HONC consists of 10 items focusing on loss of control over smoking. Responses were recorded dichotomously (yes/no). A sum score was calculated over all items and the scale had good internal consistency (Cronbach's Alpha $=.87$ )

A previous quit attempt in the past 6 months before the start of the intervention was assessed with one question ("Have you made a serious quit attempt in the last 6 months?"). Responses were recorded dichotomously (yes/no).

Quit motivation at baseline was assessed with one item ("How motivated are you to quit smoking?"). Responses were recorded on a 4-point scale (not at all - very).

\section{Primary outcome}

The primary outcome, smoking abstinence at 6-month follow-up, was assessed with 1 question ("On how many of the last 30 days have you smoked cigarettes?"). Participants were coded abstinent, if they indicated no smoking on any of the past 30 days. We biochemically verified smoking behavior self-reports with a subsample of $n=186$ students using exhaled carbon monoxide (CO). When setting a 9 parts per million CO cutoff (Society for Research on Nicotine and Tobacco, 2002), self-reported smoking within the past 7 days (assessed with a separate question) matched exhaled CO results in $75,3 \%$ of all cases (59,7\% correct negative, $15,6 \%$ correct positive). Very few students $(3,2 \%)$ reported non-smoking and tested above the CO-cutoff. However, 21,5\% of students reported smoking and tested below the cutoff.

\section{Statistical analyses}

Baseline differences between the IG and the CG were calculated using t-tests and $\mathrm{Chi}^{2}$ tests. Group differences on the primary outcome measure were analyzed using logistic regression analyses with robust standard errors accounting for the clustered data structure with students nested in schools, and controlling for baseline differences on covariates, using STATA 14.0 (StataCorp, 2015). Missing data on baseline measures were low overall with a maximum of $6,1 \%$ on the variable quit motivation. All missing values at baseline were estimated using the Mplus FIML (full-information-maximum-likelihood) procedure (Hedeker, Mermelstein \& Demirtas, 2007).

We conducted complete case and intent-to-treat (ITT) analyses (West, Hajek, Stead, \& Stapleton, 2005). For ITT analyses, missing values on the outcome measure past 30-day smoking abstinence at 6-month follow-up (IG: $n=81,29,8 \%$; CG: $n=98$, $40,8 \%$ ) were considered non-abstinent. We also conducted additional sensitivity analyses using Mplus FIML. The reason for these sensitivity analyses was that previous studies suggested ITT analyses may bias results in favor of the IG, especially under conditions of more missing data in the CG compared to the IG (Idrisov et al., 2013), which was the case in the current study. Sensitivity analyses using Mplus FIML allowed us to use all cases including those with missing outcome data. Models were estimated using Mplus maximum likelihood estimation with robust standard errors controlling for schools as clusters and montecarlo integration.

\section{Results}

\section{Baseline characteristics and IG-CG equivalence}

Baseline characteristics of the entire sample and differences between the IG and the CG are displayed in Table 1. Participants' mean age was 14.8 years and almost half of them were female $(46,3 \%)$. On average, participants reported smoking 7.3 cigarettes per day in the past 30 days and a score of 5.4 on the HONC (scale from $0-10)$. Almost half of participants $(40,6 \%)$ reported a quit attempt within the past 6 months and were overall fairly motivated to quit (average score of 2.6 on a scale from $1-4)$. Compared to adolescent smokers in the CG, intervention participants smoked more heavily, reported a higher score on the HONC, 
Table 1: Baseline characteristics and IG-CG equivalence

\begin{tabular}{|l|c|c|c|c|l|}
\hline & $\mathbf{N}$ & Entire sample & IG & CG & t/Chi \\
\hline Age & 512 & $14.81(1.13)$ & $14.83(1.14)$ & $14.78(1.14)$ & 0.5 \\
Gender female & 512 & $46.3 \%(237)$ & $48.2 \%(131)$ & $44.2 \%(106)$ & 0.8 \\
CPD & 512 & $7.29(7.04)$ & $8.19(7.00)$ & $6.27(6.97)$ & $3.1^{* *}$ \\
HONC & 510 & $5.39(3.25)$ & $5.91(3.17)$ & $4.81(3.26)$ & $3.9^{* * *}$ \\
Quit attempt & 485 & $40.6 \%(197)$ & $45.1 \%(114)$ & $35.8 \%(83)$ & $4.3^{*}$ \\
Quit motivation & 481 & $2.64(0.97)$ & $2.92(0.87)$ & $2.32(0.99)$ & $7.0^{* * *}$ \\
\hline
\end{tabular}

Note: $\mathrm{CG}=$ Control group $\mathrm{CPD}=$ Cigarettes per day; $\mathrm{HONC}=$ Hooked on Nicotine Checklist $\mathrm{IG}=$ Intervention group

had a higher likelihood to have tried to quit in the past 6 months, and reported a higher quit motivation (Table 1). Therefore, baseline cigarettes per day, HONC scores, previous quit attempts, and quit motivation were included as covariates in all analyses investigating the primary outcome. Intervention schools did not differ from control schools with regard to school type, size, urban vs. rural location, school surroundings, or school tobacco policies (data not shown).

\section{Dropout analyses}

About one third of participants had incomplete data at 6-month follow-up $(n=179,35,0 \%$; IG: $n=81,29,8 \%$; CG: $n=98,40,8 \%$ ), because they were not present in class at the time of the assessment $(n=175)$ or did not report their smoking behavior $(n=4)$. Participants with incomplete data at follow-up did not significantly differ from retained participants on any of the baseline characteristics (data not shown).
A comparison of participants with incomplete follow-up data between groups showed that participants with incomplete data in the IG had higher quit motivation at baseline compared to participants with incomplete follow-up data in the CG (IG: $M=3.11, S D=0.82$; $\mathrm{CG}$ : $M=2.09, S D=0.92 ; t=7.6, p<.001)$. There were no other significant between-group differences among participants with incomplete follow-up data.

\section{Outcome analyses}

At the end of the sixth treatment session, 32,0\% of adolescents in the IG reported past 7-day abstinence and $26,5 \%$ reported 30 -day abstinence at the end of the 4-week follow-up care period. Regarding our primary outcome of self-reported 30-day smoking abstinence at the 6-month follow-up, 38 participants in the IG (19,9\% of complete cases, $14,0 \%$ ITT) and 12 participants in the CG (8,5\% of complete cases, 5,0\% ITT) reported smoking abstinence. Three regression

Table 2: Results of three regression models (complete case, ITT, FIML) to test the intervention effect on smoking abstinence at 6-month follow-up.

\begin{tabular}{|c|c|c|c|}
\hline$N$ & $\begin{array}{l}\text { Complete case } \\
N=333,50 \text { clusters } \\
(a O R, 95 \% \mathrm{Cl})\end{array}$ & $\begin{array}{c}\text { ITT } \\
N=512,51 \text { clusters } \\
(\text { aOR, } 95 \% \mathrm{Cl})\end{array}$ & $\begin{array}{c}\text { FIML } \\
\begin{array}{c}N=512,51 \text { clusters } \\
(a O R, 95 \% \mathrm{Cl})\end{array}\end{array}$ \\
\hline $\begin{array}{l}\text { Condition } \\
\text { CPD } \\
\text { HONC } \\
\text { Quit attempt } \\
\text { Quit motivation }\end{array}$ & $\begin{array}{l}2.74[1.17 ; 6.39]^{*} \\
0.93[0.85 ; 1.00] \\
1.07[0.93 ; 1.24] \\
1.78[0.92 ; 3.45] \\
1.58[1.00 ; 2.49]\end{array}$ & $\begin{array}{l}2.73[1.19 ; 6.27]^{*} \\
0.93[0.86 ; 1.00] \\
1.05[0.91 ; 1.21] \\
1.92[0.97 ; 3.81] \\
1.51[1.01 ; 2.26]^{*}\end{array}$ & $\begin{array}{l}2.71[1.16 ; 6.31]^{*} \\
0.93[0.85 ; 1.00] \\
1.07[0.93 ; 1.24] \\
1.72[0.89 ; 3.30] \\
1.61[1.02 ; 2.56]^{*}\end{array}$ \\
\hline
\end{tabular}

Note: $\mathrm{aOR}=$ Adjusted Odds Ratio, $\mathrm{CPD}=$ Cigarettes per day; $\mathrm{FIML}=$ Full information maximum likelihood; $\mathrm{HONC}=$ Hooked on Nicotine Checklist; ITT $=$ Intention to treat 
models testing statistical significance of these findings are displayed in Table 2. All models (complete case, ITT, and FIML) produced similar results: When compared to the CG, participants in the IG consistently had 2.7 fold higher adjusted odds of being abstinent at the 6-month follow-up when controlling for baseline covariates cigarettes per day, HONC score, a past 6-month quit attempt, and quit motivation. The only covariate that significantly predicted abstinence status at follow-up over and above group membership was quit motivation in the ITT and FIML models. Quit motivation marginally predicted abstinence in the complete case model $(p=.05)$ and cigarettes per day was marginally significant in the ITT model $(p=.05)$.

The intervention achieved an absolute risk reduction $(A R R)$ of $9 \%$, a risk ratio $(R R)$ of 2.8 , and a relative risk reduction $(R R R)$ of $1.8 \mathrm{com}$ pared to the control condition (unadjusted ratios).

\section{Engagement}

Intervention participants attended an average of $4.8(S D=1.7)$ intervention sessions. Participants reporting abstinence at follow-up attended an average of $5.2(S D=1.5)$ sessions compared to $4.7(S D=1.7)$ sessions among non-abstinent participants (complete case); this difference approached statistical significance $(t=1.9$, $p=.057)$.

\section{Discussion}

The aim of this study was to examine the effectiveness of a school-based smoking cessation intervention for students from German secondary schools with an overrepresentation of students with low SES. At 6-month follow-up, intervention participants reported a significantly higher abstinence rates (19,9\% of complete cases, $14,0 \%$ ITT analysis) compared to controls $(8,5 \%$ of complete cases, $5,0 \%$ ITT analysis). Intervention participants had adjusted odds of 2.7 of being smoke free at follow-up compared to CG members.
The most recent meta-analysis of ASCIs (Fanshawe et al., 2017) estimates a risk ratio of $R R=1.35$ (95\% CI 1.03-1.77) for programs using group counselling as delivery method (compared to 2.8 in our study). When classified according to theoretical basis of the interventions, meta-analyses indicate a $R R$ of $1.40(95 \%$ CI 1.14-1.74) for interventions based on a complex theoretical model using stages of change, motivational interviewing, cognitive behavioral therapy, and/or social cognitive theory, compared to controls (Fanshawe et al., 2017). Finally, the program most similar to our intervention with regard to rationale, content, and setting (Project-EX in continuation schools) resulted in a cessation rate of $17 \%$ in the intervention group compared to $8 \%$ in the control group (ITT analysis, 30-day abstinence five months after quit day; Sussman et al., 2001). Compared to these studies, "losgelöst" seems to perform better than ASCIs in general and as well as a program of the same type.

On the other hand, $86 \%$ of participants (ITT analysis) were still smoking half a year after the end of the intervention. A decrease in abstinence rates over time has been observed in other cessation interventions for adolescents, and previous work suggested improving ASCIs by tailoring them to adolescent- and genderspecific needs or by providing more counselorinitiated contacts (Simon et al., 2015). While our intervention addressed these aspects (e.g., the intervention was informed by theories of adolescent development, contained genderspecific relapse-prevention content, an individual session, and pro-active contacts during follow-up care), fading quit rates call for more intense extended support than the current intervention provided ( 1 call, 6 text messages). Bailey et al. (2013) achieved cessation rates of $21 \%$ by adding 9 additional group counseling sessions to a 10 -week school-based cessation intervention, which included cognitive-behavioral counseling and nicotine replacement therapy (compared to $7 \%$ abstinence rates in a non-extended study arm). ASCIs may also be improved by modifying program content: Pro- 
moting overall motivation to quit seems to be of key importance (McCuller, Sussman, Wapner, Dent \& Weiss, 2006), which fits well with our results showing that quit motivation at baseline significantly predicted abstinence at follow-up. These findings suggest that further extending booster sessions in the follow-up period focusing on participants' quit motivation may substantially enhance the intervention.

Besides extending intervention time or content, previous research has also linked an increase of effectiveness to a more thorough implementation of interventions (Durlak \& DuPre, 2008). However, the corresponding number of $32 \%$ quitters at the end of the 6 sessions in the current effectiveness study is fairly similar to the results of the previous pilot (37\%) and feasibility (30\%) studies (Bühler et al., 2012). This indicates similar implementation quality despite real-world conditions.

The current study has several limitations. First, participants were recruited from specific German schools and the sample can therefore not be regarded as representative of adolescent smokers in Germany. Students who participated in the current study were not deliberately screened and selected based on their SES and likely had diverse backgrounds, which means findings do not exclusively apply to a low SES population. However, the German Education Report has shown that the majority of German Haupt-/Mittelschulen are characterized by a student body with a low SES background (Autorengruppe Bildungsberichterstattung, 2018) and thus it is reasonable to expect that the majority of students participating in this trial had low SES as well. Second, assignment to conditions was non-randomized and alternative causes of intervention effects cannot be ruled out. We tested baseline equivalence of intervention and control schools and did not find significant differences. However, we found baseline differences between students in the IG and the CG, and these variables were subsequently included as covariates in the statistical analyses. Third, our measures were based on retrospective self-reports, which are prone to recall bias and under- or over-reporting. Further, only a subsample of participants completed biochemical verification of smoking self-reports using exhaled CO. While our biochemically verified results do not suggest under-reporting of smoking, a substantial group of participants $(21,5 \%)$ may have over-reported. A potential reason for this mismatch may be the combination of a short halflife of breath CO of 2 to 3 hours (Marrone, Paulpillai, Evans, Singleton \& Heishman, 2010) and irregular smoking patterns among adolescents. However, it should be noted that selfreports of smoking are generally considered valid (Patrick et al., 1994) and the current study included the usual precautions to ensure their validity. Moreover, the current study did not investigate to what extent intervention trainers impacted smoking cessation outcomes, which should be explored in future studies. Also, additional research is needed on the economic efficiency of the tested intervention, which is rather resource-intensive.

The current study also has significant strengths: Results were derived from an effectiveness study with the intervention carried out in real-world school settings and by trained professionals not involved in program development. Appropriate statistical analyses were applied to account for intraclass correlation and loss of participants to follow-up. Implementation checks showed that participants attended a high number of intervention sessions, the primary outcome was assessed at 6-months follow-up, and our sample size allowed to test the primary hypothesis with pre-specified power.

In conclusion, the "losgelöst" intervention is an adolescent-specific smoking cessation intervention that is theory-based, feasible, and accepted by the target population. Compared to a CG, 30-day smoking abstinence among participants increased by almost factor 3 $(R R=2.8)$ half a year after the intervention. As the intervention was designed for students attending schools of a lower educational track, it focused on a target population with higher smoking rates and a need for effective cessation interventions. 


\section{References}

Autorengruppe Bildungsberichterstattung (Hrsg.) (2018). Bildung in Deutschland 2018. Ein indikatorengestützter Bericht mit einer Analyse zu Wirkungen und Erträgen von Bildung. Bielefeld. https://www.destatis.de/DE/Themen/ Gesellschaft-Umwelt/Bildung-Forschung-Kultur/Bil dungsstand/Publikationen/Downloads-Bildungs stand/bildung-deutschland-5210001189004.pdf? blob=publicationFile

Bailey, S. R., Hagen, S. A., Jeffery, C. J., . . Killen, J. D. (2013). A randomized clinical trial of the efficacy of extended smoking cessation treatment for adolescent smokers. Nicotine Tob Res, 15 (10), 1655-1662. https://doi.org/ $10.1093 / \mathrm{ntr} / \mathrm{ntt} 017$

Brown, S., McGue, M., Maggs, J., Schulenberg, J., Hingson, R., Swartzwelder, S. ... Murphy, S. (2008). A developmental perspective on alcohol and youths 16 to 20 years of age. Pediatrics, $121,290-310$. https://doi. org/10.1542/peds2007-2243D

Branstetter, S. A., Horn, K., Dino, G., Zhang, J. J. (2009). Beyond quitting: Predictors of teen smoking cessation, reduction and acceleration following a school-based in tervention. Drug Alc Dep, 99(1-3), 160 - 168. https:// doi.org/10.1016/j.drugalcdep.2008.07.011

Bühler, A., Geier, A. \& Metz, K. (2009). Entwicklung eines neuen, jugendspezifischen Ausstiegsprogramms für jugendliche Raucher. IFT Abschlussbericht. Unveröffentlichter Bericht. München: IFT Institut für Therapieforschung.

Bühler, A. \& Thrul, J. (2012). Rauchstopp bei jungen Rauchenden. Grundlagen und Intervention. Sucht, 58(5), 297-316. https://doi.org/10.1024/0939-5911.a000 204

Bühler, A., Wegmann, L., Schmidt, A., Thrul, J., Strunk, M. \& Lang, P. (2012). Rekrutierung, Implementation und Aufhörrate eines Rauchstopp-Kurses für Jugendliche. Sucht, 58(1), 23-32. https://doi.org/10.1024/ 0939-5911.a000158

DiFranza, J. R., Savageau, J. A., Rigotti, N. A., Fletcher, K., Ockene, J. K., McNeill, A. D., Coleman, M. \& Wood, C. (2002). Development of symptoms of tobacco dependence in youth: 30 month follow up data from the DANDY study. Tob Control, 11, 228-235.

Durlak, J. A. \& DuPre, E. P. (2008). Implementation matters: A review of research on the influence of implementation on program outcomes and the factors affecting implementation. Am J Community Psychol, 2008 41, 327-350. https://doi.org/10.1007/s10464-0089165-0

Fanshawe, T. R., Halliwell, W., Lindson, N., Aveyard, P., Livingstone-Banks, J. \& Hartmann-Boyce, J. (2017). Tobacco cessation interventions for young people. Cochrane Database of Systematic Reviews, Issue 11. Art. No.: CD003289. https://doi.org/10.1002/14651858. CD003289.pub6

Hedeker, D., Mermelstein, R. J. \& Demirtas, H. (2007). Analysis of binary outcomes with missing data: missing $=$ smoking, last observation carried forward, and little multiple imputation. Addiction, 102, 1564-1573. https://doi.org/10.1111/j.1360-0443.2007.01946.x

Idrisov, B., Sun, P., Akhmadeeva, L., Arpawong, T., Kukhareva, P. \& Sussman, S. (2013). Immediate and six-month effects of project ex russia: A smoking cessation intervention pilot program. Addict Behav, 38, 2402-2408. https://doi.org/10.1016/j.addbeh.2013.03.013
Jessor, R. (1992). Risk behavior in adolescence: A psychosocial framework for understanding and action. Dev Rev. 12, 374-390.

Kandel, D. B., Hu, M. C., Griesler, P.C. \& Schaffran, C. (2007). On the development of nicotine dependence in adolescence. Drug Alc Dep, 91, 26-39.

Kraus, L., Piontek, D., Pabst, A. \& Gomes de Matos, E. (2013). Studiendesign und Methodik des Epidemiologischen Suchtsurveys. Sucht, 59, 309-320. https:// doi.org/10.1024/0939-5911a000274

Kuntz, B., Waldhauer, J., Zeiher, J., Finger, J. \& Lampert, T. (2018). Soziale Unterschiede im Gesundheitsverhalten von Kindern und Jugendlichen in Deutschland Querschnittsergebnisse aus KIGGS Welle 2. I Health Monit, 3(2), 45-59. https://doi.org/10.17886/RKIGBE-2018-067

Marrone, G. F., Paulpillai, M., Evans, R. J., Singleton, E. G. \& Heishman, S.J. (2010). Breath carbon monoxide and semiquantitative saliva cotinine as biomarkers for smoking. Hum Psychopharmacol, 25, 80-83. https:// doi.org/10.1002/hup.1078

McCuller, W.J., Sussman, S., Wapner, M., Dent, C. \& Weiss, D. (2006). Motivation to quit as a mediator of tobacco cessation among at-risk youth. Addict Behav, 31, $880-888$.

Moffitt, T. (1993). Adolescence-limited and life-coursepersistent antisocial behavior: a developmental taxonomy. Psych Rev, 100, 674-701.

Patrick, D. L., Cheadle, A., Thompson, D. C., Diehr, P., Koepsell, T. \& Kinne, S. (1994). The validity of selfreported smoking: A review and meta-analysis. $A m J$ Public Health, 84, 1086-1093.

Orth, B. \& Merkel, C. (2018). Rauchen bei Jugendlichen und jungen Erwachsenen in Deutschland. Ergebnisse des Alkoholsurveys 2016 und Trends. BZgA-Forschungsbericht. Köln: Bundeszentrale für gesundheitliche Aufklärung. https://doi.org/10.17623/BZGA:225-ALK SY16-RAU-DE-1.0

Schneewind, K. (2005). Familienpsychologie (2. Aufl.). Stuttgart: Kohlhammer

Simon, P., Kong, G., Cavallo, D. A. \& Krishnan-Sarin, S (2015). Update of adolescent smoking cessation interventions: 2009-2014. Curr Addict Rep, 15 (2), 15-23. https://doi.org/10.1007/s40429-015-0040-4

Society for Research on Nicotine and Tobacco (SRNT) Subcommittee on Biochemical Verification (2002). Biochemical verification of tobacco use and cessation. Nicotine Tob Res, 4, 149-159.

StataCorp (2015). Stata Statistical Software: Release 14. College Station, TX: StataCorp LP.

Sussman, S., Dent, C. \& Lichtman, K. (2001). Project EX outcomes of a teen smoking cessation program. Addict Behav, 26, 425-38.

Sussman S. \& Sun P. (2009). Youth tobacco use cessation: 2008 update. Tobacco Induc Dis, 5 (3). https://doi.org/ $10.1186 / 1617-9625-5.5$

Thrul, J., Stemmler, M., Bühler, A. \& Goecke, M. (2014). The role of participants' self-selected future smoking goals in adolescent smoking cessation interventions. Drug Alc Dep, 141, 118-123. https://doi.org/10.10 16/j.drugalcdep.2014.05.016

Thrul, J., Stemmler, M., Goecke, M. \& Bühler, A. (2015). Are you in or out? Recruitment of adolescent smokers into a behavioral smoking cessation intervention. $A d-$ dict Behav, 45, 150 - 155. https://doi.org/10.1016/j. addbeh.2015.01.030 
10 Anneke Bühler, Johannes Thrul, Michaela Goecke, Annette Schmidt

Wegmann, L., Bühler, A., Strunk, M., Lang, P. \& Nowak D. (2012). Smoking cessation with teenagers: The relationship between impulsivity, emotional problems, program retention and effectiveness. Addict Behav, 37(4), 463-468. https://doi.org/10.1016/j.addbeh.2011. 12.008

West, R., Hajek, P., Stead, L., \& Stapleton, J. (2005). Outcome criteria in smoking cessation trials: Proposa for a common standard. Addiction, 100(3), 299-303 https://doi.org/10.1111/j.1360-0443.2004.00995.x

Zeiher, J., Lange, C., Starker, A., Lampert, T. \& Kuntz, B. (2018). Tabak- und Alkoholkonsum bei 11- bis 17-Jährigen in Deutschland - Querschnittsergebnisse aus KIGGS Welle 2 und Trends. J Health Monit, 3(2) 23-43. https://doi.org/10.17886/RKI-GBE-2018-066

\section{Prof. Dr. Anneke Bühler}

Hochschule Kempten

University of Applied Sciences

Fakultät Soziales und Gesundheit

Bahnhofstr. 61

D-83745 Kempten

E-Mail: anneke.buehler@hs-kempten.de
Asist.-Prof. Dr. Johannes Thrul

Johns Hopkins University

Johns Hopkins Bloomberg School

of Public Health

Department of Mental Health

624 N Broadway

Baltimore, MD 21205, USA

E-Mail: jthrul@jhu.edu

\section{Michaela Goecke, M.A.}

Bundeszentrale für gesundheitliche

Aufklärung (BZgA)

Referat Maarweg 149-161

D-50825 Köln

E-Mail: michaela.goecke@bzga.de

\section{Dr. Annette Schmidt}

IFT Institut für Gesundheitsförderung

Leopoldstr. 175

D-80804 München

E-Mail: Schmidt@ift-gesundheit.de 